\title{
O CONTROLE JUDICIAL DA EFETIVIDADE DOS DIREITOS SOCIAIS: A PERSPECTIVA DA TEORIA FILOSÓFICO-POLÍTICA DA CONDIÇÃO HUMANA E ESPAÇO PÚBLICO E DA CRÍTICA HERMENÊUTICA DO DIREITO
}

\author{
Fausto Santos Morais* \\ Giuliana Redin ${ }^{*}$
}

\begin{abstract}
RESUMO: Decorridos mais de vinte anos da Constituição de 1988 perceber-se que os direitos sociais, tidos como fundamentais, ainda apresentam grande dificuldade de serem efetivos ou socilamente eficazes, no sentido de existirem políticas públicas suficientes à sua concretização. Com o objetivo de desenvolver hipóteses teóricas que enfrentem esse problema, esse ensaio aborda duas perspectivas teóricas diferentes para justificar a legitimidade do controle judicial da efetividade dos direitos sociais. A primeira, baseada na metodologia desconstrutivista, está associada ao pensamento filosófico-político arendtiano da condição humana e do espaço público. O segundo, fundado na metodologia fenomenológica hermenêutica, busca enfrentar a utilização do método ponderativo nas demandas judiciais que reclamam o controle das políticas públicas relativo a sua efetividade. Nesse sentido, são apresentadas as linhas teóricas que convergem na necessidade de acesso ao Judiciário como mecanismo de efetividade dos direitos sociais.

Palavras-chave: Efetividade dos direitos sociais. Crítica Hermenêutica do Direito. Condição humana e Espaço Público.

ABSTRACT: Has passed more than twenty years of the 1988's Constitution, to realize that social rights, as fundamental rights, shows large difficulty to be social effective or efficient yet, becouse aren't sufficient publics policies to come true them. Doing development theoretical possibilities to cross over this problem, this paper focus in two different theoretical perspectives to justify the legitimacy of judicial review of the effectiveness of social rights. The first, based on deconstructive methodology, is associated with the philosophical and political thought of Arendt about the human condition and the public space. The second, based on hermeneutic phenomenological methodology, does to use the balancing's method in juditial review for to accountabillity effectivenes about public policies. It is the through Law's Hermeneutic Criticism. In this sense, are present the theoretical lines that converge on the need for access to the Judiciary as a mechanism of effectiveness of social rights.
\end{abstract}

Keywords: Social's Rights's Effectiveness. Law's Hermeneutic Criticism. Public Space and Human Condition.

\section{INTRODUÇÃO}

A considerar que o acesso à justiça é direito fundamental, quais as potencialidades de controle da efetividade dos direitos sociais pelo Poder Judiciário? Movido por essa indagação, o presente texto se propõe a enfrentar

\footnotetext{
* Doutorando em Direito Público (UNISINOS/RS). Mestre em Direito Público (UNISINOS/RS), Especialista em Direito Tributário (UPF/RS), professor e pesquisador da Faculdade Meridional IMED/RS, integrante do Grupo de pesquisa "Direitos Humanos e espaço público: efetivação do direito à cidade no município de Passo Fundo - RS - Brasil.” Advogado.

** Doutora em Direito ela PUC-PR. Mestre em Direito Público pela Universidade Luterana do Brasil. Mestre em desenvolvimento, gestão e cidadania pela Universidade regional do noroeste do RS. Professora das disciplinas de Direitos Humanos e Direito Internacional da Faculdade Meridional e pesquisadora pela Fundação Meridional, integrante do grpo de pesquisa "Direitos Humanos e espaço público: efetivação do direito à cidade no município de Passo Fundo - RS - Brasil.”
}

Revista de Estudos Jurídicos, a. 15, n. 22, 2011 
sob duas perspectivas teóricas diferentes, contudo, complementares, a questão quanto à efetividade - eficácia social ${ }^{15}$, das políticas públicas eleitas para concretização dos direitos fundamentais sociais no Brasil.

A primeira perspectiva apresenta o debate sobre esfera pública e acesso ao espaço público na concepção filosófico-política arendtiana, que demanda a compreensão de categorias universais sobre necessidades básicas e, portanto, sua associação à condição humana, como pressuposto de direitos humanos fundamentais. Nesse sentido, essa hipótese teórica justifica a legitimidade e ampla possibilidade de controle judicial da efetividade de direitos sociais, a partir do pressuposto de acesso do indivíduo ao espaço público.

Como uma segunda abordagem teórica, será desenvolvida a chamada Crítica Hermenêutica ao Direito como apoio para questionar o controle judiciário das políticas públicas que consagram direitos sociais, cujas decisões acabam se valendo da ponderação como método hábil para a solução de conflitos que, em parte significativa, decorre da existência de conflito entre princípios jurídicos. Propõe-se, portanto, indicar as limitações desse método através da hermenêutica voltada aos imperativos democráticos.

Diante das duas propostas de abordagem indicadas, o trabalho está organizado em duas seções: a primeira (secção 2), concentra-se na efetividade dos direitos sociais a partir da concepção filosófico-política da condição humana e do espaço público; a segunda (secção 3) indaga sobre o controle da efetividade das políticas públicas através do Poder Judiciário: breve questionamento hermenêutico sobre a utilização do método ponderativo. Ambas as perspectivas articulam argumentos teóricos hábeis para enfrentar o problema proposto da efetividade/eficácia social dos direitos sociais.

\section{EFETIVIDADE DOS DIREITOS SOCIAIS A PARTIR DA CONCEPÇÃO FILOSÓFICO-POLÍTICA DA CONDIÇÃO HUMANA E DO ESPAÇO PÚBLICO}

Os direitos sociais, ligados às prestações positivas do Estado de distribuição de políticas públicas para a promoção de bem-estar social, possuem sua eficácia social ou efetividade associada às condições orçamentárias e escolhas democráticas. Contudo, do ponto de vista filosófico-político da condição humana e do espaço público a compreensão de eficácia social de direitos sociais e a potencial judicialização pode ser visualizada sob uma ótica jurídica diferente da teoria crítica hermenêutica do direito, que será

\footnotetext{
${ }^{15} 15$ A expressão "eficácia social" será utilizada em equiparação a "efetividade" dos direitos sociais, no sentido da efetiva consecução na realidade dos objetivos pretendidos normativamente, como articula, por exemplo, José Afonso da Silva: “(...) tratando-se de normas jurídicas, se fala em eficácia social em relação à efetividade, porque o produto final objetivado pela norma se consubstancia no controle social que ela pretende, enquanto eficácia jurídica é apenas a possibilidade de que isso venha a acontecer." Cf. SILVA, José Afonso. Aplicabilidade das normas constitucionais. 6. ed. São Paulo: Malheiros Editores, 2004, p. 66.
} 
desenvolvida na próxima secção. A compreensão do espaço público permite não apenas o enfraquecimento de um primeiro argumento que cria a barreira para a eficácia social judicial de direitos sociais, que é o de que políticas públicas estão necessariamente vinculadas à previsão orçamentária, que decorre das escolhas públicas sob o pressuposto hermético constitucional de democracia representativa. Também viabiliza a fragilização de um segundo argumento, de que os direitos sociais teriam sua eficácia restrita ao limite orçamentário ou à reserva do possível, cuja tese iniciada na década de setenta na Alemanha que tomou corpo internacional como artifício teórico justificante para a não adoção e determinadas prestações públicas ${ }^{16}$.

Essas teorias são o produto de uma construção do imaginário jurídico, que não necessariamente correspondem do ponto de vista político e jurídico teorias válidas e sustentáveis diante do que se pode conceber por "espaço público" e "necessidades humanas", conceitos ligados ao Direito pensado como justiça. Ambos esses conceitos, desconstroem essas teorias, que são artifícios legitimados pela "força de lei", que reduzem os direitos sociais à escolhas herméticas "democráticas" de orçamento público e à reserva do possível. Nesse sentido, é sempre memorável a célebre análise de Jacques Derrida, em sua obra Força de Lei, que desconstrói o dogma da essência da justiça como o Direito fundado, produto da autoridade do legislador, da comodidade do soberano, da segurança e do chamado "fundamento místico da autoridade"17. Trata-se de reiterar o positivismo jurídico na concepção neoconstitucional. Portanto, desconstruir é retomar a essência da justiça para além da crença do fundamento místico do Direito como autoridade; trata-se, segundo Derrida ${ }^{18}$, de compreender a justiça como um “'talvez", pois "é preciso sempre dizer talvez quanto à justiça. Há um porvir para a justiça, e só há justiça na medida em que seja possível o acontecimento que, como acontecimento, excede ao cálculo, às regras, aos programas, às antecipações etc." Para Derrida "a justiça, como experiência da alteridade absoluta, é inapresentável, mas é a chance do acontecimento e a condição da história" ${ }^{19}$.

Isso quer dizer que em se tratando de direitos sociais, a eficácia social é extremamente complexa e não pode ser completamente antecipada, negociada ou fechada na concepção do orçamento público, tampouco refletida a partir de

\footnotetext{
16 A teoria da reserva do possível é amplamente utilizada nos debates judiciais e reconhece, segundo Sarlet (A eficácia dos direitos fundamentais. 2 ed. Porto Alegre: Livraria do Advogado, 2001), que a efetivação dos direitos sociais encontra-se na dependência da efetiva disponibilidade de recursos por parte do Estado, constituindo tarefa do legislador ordinário decidir sobre a aplicação e destinação de recursos públicos, inclusive no que tange às prioridades na esfera das políticas públicas, pela lei orçamentária. Trata da teoria que ressalva a possibilidade de judicialização de políticas públicas na hipótese de comprovação de ausência de recursos orçamentários suficientes para atender o direito social.

${ }^{17}$ DERRIDA, Jacques. Força de Lei. São Paulo: Martins Fontes, 2007, p. 20. A expressão teórica "fundamento místico da autoridade" é atribuída por Derrida à Montaigne.

${ }^{18}$ Ibid., p. 55.

${ }^{19}$ Ibid. loc. cit.
} 
uma teoria de reserva do possível, uma vez que a dinâmica financeira do Estado, também absolutamente distinta de uma dinâmica financeira privada, cujos instrumentos de finanças são oriundos de um espaço privado de ação.

Necessidades humanas. Esta é a concepção filosófico-política que dá sentindo aos direitos sociais, como direitos humanos fundamentais. Na visão de Pereira $^{20}$, necessidades mínimas e básicas são concepções distintas: "enquanto o primeiro tem a conotação de menor, de menos, em sua acepção mais ínfima identificada com patamares de satisfação de necessidades que beiram a desproteção social", necessidades básicas expressam "algo fundamental, principal, primordial, que serve de base de sustentação indispensável e fecunda ao que ela se acrescenta". As necessidades humanas, tuteladas expressamente a partir dos direitos fundamentais, em especial os sociais, são as necessidades humanas básicas e não mínimas. É nesse sentido que diz Pereira ${ }^{21}$, "enquanto o mínimo pressupõe supressão ou cortes de atendimentos, tal como propõe a ideologia liberal, o básico requer investimentos sociais de qualidade para preparar o terreno a partir do qual maiores atendimentos podem ser prestados e otimizados".

Mas como definir essas necessidades básicas e revelar o nível de eficácia social de ações públicas para a respectiva efetivação. Por necessidades básicas, Pereira define a partir de um dado fundamento que "confere às necessidades básicas (e somente a elas) uma implicação particular: a ocorrência de sérios prejuízo ${ }^{22}$ à vida material dos homens e à atuação destes como sujeitos (informados e críticos), caso essas necessidades não sejam adequadamente satisfeitas" 23 . Nesse aspecto, seria importante a definição para "satisfação de necessidades". Aqui, a considerar a compreensão de que de que necessidades básicas são objetivamente comuns a todos, Pereira ${ }^{24}$, valendo-se do referencial teórico de Doyal e Gough, diz que "há uma variedade enorme de satisfiers bens, serviços, atividades, relações, medidas, políticas - que, em maior ou menor extensão, podem ser empregados para atender a essas necessidades", como por exemplo, as peculiaridades relativas à alimentação e à moradia que são variáveis em relação à cultura de cada povo. Portanto, necessidade básica está vinculada aos elementos objetivos potenciais para que se possa exercer o direito de ação no espaço público, isto é, trata-se da satisfação das necessidades básicas materiais biológicas, mas também intelectuais e criativas. Assim, juntamente com o rol de garantias de direitos sociais insculpido no artigo $6^{\circ}$ da Constituição Federal, a gama de leis infraconstitucionais correlatas, políticas

${ }^{20}$ PEREIRA, Potyara A. P. Necessidades humanas: subsídios a crítica dos mínimos sociais. São Paulo: Cortez, 2000, p. 26.

${ }^{21}$ Ibid., loc. cit.

${ }^{22}$ Para o autor, "sérios prejuízos são os impactos negativos cruciais que impedem ou põem em sério risco a possibilidade objetiva dos seres humanos de viver física e socialmente em condições de poder expressar a sua capacidade de participação ativa e crítica" (PEREIRA, 2000, p. 67).

${ }^{23}$ Ibid., loc. cit.

${ }^{24}$ Ibid., 2000, p. 75. 
públicas e serviços, é fundamental para a satisfação de necessidades básicas sociais o diálogo com as especificações e demandas locais.

Isso quer dizer que restringir o acesso aos direitos sociais a quotas orçamentárias e a políticas públicas oriundas da "escolha geral e mínima" por parte do Administrador é o mesmo que violá-los sob o pálio da própria lei. É o abuso do Estado ou a privatização das questões públicas. Nesse sentido, é oportuno referir o significado do público, primeiro, pelo conceito de esfera pública. Para Hannah Arendt ${ }^{25}$, "a presença de outros que veem o que vemos e ouvem o que ouvimos garante-nos a realidade do mundo e de nós mesmos", e ainda "ser visto e ouvido por outros é importante pelo fato de que todos veem e ouvem em ângulos diferentes"26. Além disso, para Hannah Arendt é na esfera pública que a realidade transita e transcende a figura do próprio homem: "durante muitas eras antes de nós - mas já não agora - os homens ingressaram na esfera pública por desejarem que algo seu, ou algo que tinham em comum com os outros, fosse mais permanente que as suas vidas terrenas" 27 , por isso que "a desgraça da escravidão consistia não só no fato de que o indivíduo era privado de liberdade e visibilidade, mas também no medo desses mesmos indivíduos obscuros 'de que, por serem obscuros, morreriam sem deixar vestígio algum de terem existido",28. A condição humana ${ }^{29}$ identificável objetivamente pela "natureza comum" não está situada na esfera privada, da subjetividade dos sentimentos, das paixões e dos desejos. Isso significa dizer que

Para o indivíduo, viver uma vida inteiramente privada significa,
acima de tudo, ser destituído de coisas essenciais à vida
verdadeiramente humana: ser privado da realidade que advém
do fato de ser visto e ouvido por outros, privado em relação
'objetiva' com eles decorrente do fato de ligar-se e separar-se deles
mediante um mundo comum de coisas, e privado da possibilidade de
realizar algo mais permanente que a própria vida. (grifei). ${ }^{30}$

Por isso que falar em satisfação das necessidades básicas, que justificam os direitos sociais, é antes compreender objetivamente a realidade que se apresenta e que por vezes não está abarcada exclusivamente ou pode ser antecipada de forma artificial por critérios legais previamente estabelecidos, tais como orçamento e escolhas administrativas. Direitos humanos, na concepção arendtiana, pressupõem escolhas públicas, que, por sua vez, demandam um alto grau de participação do indivíduo na vida pública, sob pena da apropriação do

\footnotetext{
${ }^{25}$ ARENDT, Hannah. A condição humana. Rio de Janeiro: Forense Universitária, 2004, p. 60

${ }^{26}$ Ibid., 2004, p. 67.

${ }^{27}$ Ibid., 2004, p. 65.

${ }^{28}$ Ibid., loc. cit., remetendo à Barrow.

29 Arendt, nessa ótica, desenvolve essas bases teóricas ao analisar a condição humana. Ela compreende o sujeito de direito no âmbito da ação, do iniciar a conduzir algo, dentro das peculiaridades da diversidade e pluralismo humano, e cuja ação, ou agir, potencialmente, transforma o homem pelo contato com as coisas da vida mundana, também produto dessa ação.

${ }^{30}$ Ibid., 2004, p. 68.
} 
próprio indivíduo em estruturas organizacionais de dominação e disciplinamento. É a possibilidade do agir, do começar, do conduzir, que pressupõem uma capacidade humana de julgamento e que também está relacionada com a possibilidade de conhecer e compreender as "externalidades" das ações na vida política. E o local dessa participação é o espaço público.

O direito à cidade, cujo conceito começou a ser desenvolvido em 1968 por Lefbvre, é representativo da ideia de espaço público. Ou seja, direito à cidade é, em suma, pensar os direitos humanos a partir do local, do bem viver em um espaço coletivo urbano e que esse espaço seja pensado a partir das demandas da coletividade que integra esse espaço. Trata-se, segundo Lefbvre ${ }^{31}$, de compreender os espaços como uma inscrição no tempo e no mundo. Isso quer dizer, que é o ritmo das populações urbanas que define o cotidiano e esse, por sua vez, é formado por múltiplos momentos, como trabalho, educação, lazer, moradia, saneamento, cultura, e bem-estar físico e mental. Dessa forma, Lefbvre conclui que o novo modelo de sociedade urbana nasce da alteração dos ritmos da sociedade de modo a propiciar o uso completo dos lugares, com total fruição de direitos. Projetando essa conceituação à questão da eficácia social dos direitos sociais, fica evidente que a satisfação das necessidades humanas básicas demanda a percepção espacial e temporal externalizada pelos sujeitos através do exercício de ação no espaço público. Não se trata aqui do direito de ação tradicional do modelo de democracia representativa, mas de ação no sentido mais amplo da palavra, de ouvir e ser ouvido, a partir da diferença que traduz a percepção espaço/temporal da realidade presente. Dessa forma, o critério orçamentário que estabelece o mínimo de $25 \%$ da receita resultante de impostos do Município para este financiar a educação ${ }^{32}$ ou o mínimo de $15 \%$ sobre a arrecadação dos Municípios para o respectivo custeio da saúde $^{33}$, tratam-se efetivamente de mínimos que não necessariamente restringem o básico. A antecipação orçamentária mínima é um referencial que não traduz o limite para o acesso ao respectivo direito, cuja satisfação poderá transcender, inclusive o poder de escolha do Administrador Público, que julga tecnicamente pela oportunidade e conveniência, mas cujo poder-dever não supre na totalidade o direito de ação do sujeito destinatário do direito no espaço público. A esfera pública não se limita ao que o legislador indica por coisa comum, tampouco o espaço público é dirigido exclusivamente a um agente: o Administrador Público.

Em relação ao direito à educação, por exemplo, basta visualizar a situação de um bairro carente de um Município que não dispõe de escolha de educação infantil. Na hipótese de existirem vagas em educação infantil em escolhas de bairros próximos, poder-se-ia considerar satisfatória a entrega administrativa da prestação social básica fundamental relativa à educação infantil? Em uma outra hipótese referente ao direito à saúde, onde constata-se, através de pesquisa científica que recolheu material biológico bucal em crianças de um bairro carente do Município,

\footnotetext{
${ }^{31}$ LEFEBVRE, Henri. $O$ direito à cidade. Trad. Rubens Eduardo Frias. São Paulo: Centauro, 2009.

${ }^{32}$ Vide artigo 212 da Constituição Federal de 1988.

${ }^{33}$ Vide EC29, artigo 77 do ACDT, da Constituição Federal de 1988.
} 
estão sofrendo os danos do excesso de fluorose na água bebida ${ }^{34}$, é possível reivindicar políticas públicas destinadas ao tratamento da saúde bucal e dos critérios de tratamento da água, em que pese o limite orçamentário destinado à saúde tenha sido extrapolado? No primeiro caso a questão não é reconhecer a necessidade básica (educação infantil), mas o grau de satisfação dessa necessidade básica, a considerar o local de habitação dos destinatários do serviço, o que inclui não apenas o serviço de educação infantil, mas também o transporte e a inserção comunitária, por exemplo. Assim, uma vez demonstrado o grau de insatisfação dos moradores de um bairro, seria perfeitamente judicializável ${ }^{35} \mathrm{o}$ direito à instauração da respectiva escola infantil, em que pese a inexistência de previsão do Administrador Publico e independente de previsão orçamentária. $\mathrm{Na}$ segunda hipótese, não poderia ser diferente a possibilidade de judicialização para ações públicas voltadas à saúde e ao tratamento da água, colocando por terra as barreiras: escolha pública de política pelo Administrador ${ }^{36}$ e orçamento público, bem como a teoria afim da reserva do possível. Trata-se aqui de falar em satisfação da necessidade básica, que não é mínima e que por vezes não pode ser antecipada artificialmente pelo legislador ou administrador.

A própria judicialização de políticas públicas sugere uma segunda problemática, que será enfrentada na secção seguinte, que busca compreender o enfrentamento do juiz dos dilemas inerentes ao controle da efetividade dos direitos sociais na perspectiva da teoria crítica hermenêutica do direito.

\section{O CONTROLE DA EFETIVIDADE DAS POLÍTICAS PÚBLICAS ATRAVÉS DO PODER JUDICIÁRIO: BREVE QUESTIONAMENTO HERMENÊUTICO SOBRE A UTILIZAÇÃO DO MÉTODO DA PONDERAÇÃO}

A Constituição da República Federativa de 1988 deve ser considerada como um marco jurídico diferenciado sobre a previsão e consolidação dos

\footnotetext{
${ }^{34}$ Resultados colhidos no respectivo projeto institucional, arquivado junto ao CEP da Faculdade Meridional de Passo Fundo, RS.

${ }^{35}$ É importante destacar que o direito de acesso ao Judiciário no tocante ao acesso à educação, está insculpido expressamente no pouco utilizado artigo $5^{\circ}$, da $\mathrm{LDB}$ que diz: "O acesso ao ensino fundamental é direito público subjetivo, podendo qualquer cidadão, grupo de cidadãos, associação comunitária, organização sindical, entidade de classe ou outra legalmente constituída, e, ainda, o Ministério Público, acionar o Poder Público para exigi-lo. § $3^{\circ}$ Qualquer das partes mencionadas no caput deste artigo tem legitimidade para peticionar no Poder Judiciário, na hipótese do $\S 2^{\circ}$ do art. 208 da Constituição Federal, sendo gratuita e de rito sumário a ação judicial correspondente. $\S 4^{\circ}$ Comprovada a negligência da autoridade competente para garantir o oferecimento do ensino obrigatório, poderá ela ser imputada por crime de responsabilidade".

${ }^{36}$ Relativamente à atuação do Administrador, como gestor e a sempre alegada preocupação com a incidência das penalidades da Lei de Responsabilidade Fiscal, o Judiciário inevitavelmente estará aberto à ponderar diante de ações que emergem à realidade pela ação do sujeito no espaço público que não pode ser antecipada, uma vez demonstrada a vinculação ao nível de satisfação de necessidade básica.
} 
Direitos Fundamentais no Estado brasileiro. É consenso entre os juristas que esta Constituição inaugura a perspectiva direcionada à consecução de grandes objetivos sociais ainda não obtidos por grande parte da sociedade brasileira.

Entre outras finalidades a Constituição de propõe a erradicar a pobreza, a marginalização, procurando reduzir as desigualdades sociais. Veja-se, para que uma Constituição assuma no seu texto essa condição, ela acaba por apontar algumas vicissitudes ainda não solvidas pelo modelo socioeconômico que orienta as relações sociais. Isto é, consagra que nas relações interpessoais a sociedade brasileira ainda se mostra refratária ao velho modelo liberal, individual e patrimonialista. Por isso, deve o Estado, guiado pela Constituição, manter as suas preocupações em oferecer instrumentos políticos que procurem equilibrar juridicamente aquilo que economicamente é diferente.

Sendo assim, parece evidente que o ethos constitucional está direcionado para um compromisso da Sociedade e do Estado, na procura de criar mecanismos que auxiliem na tarefa de tornar as condições socioeconômicas dos cidadãos mais isonômicas. Mas, como será possível estabelecer instrumentos para equilibrar as relações socioeconômicas? Uma das maneiras é o reconhecimento do papel do Estado como provedor de condições mínimas que permitam aos cidadãos a disputa econômica em paridade de armas. Trata-se do modelo do Welfare State. Somente com a intervenção estatal na vida dos cidadãos será possível municiá-los de recursos necessários para a competição necessariamente instituída pelo modelo capitalista que domina as relações econômicas desenvolvidas entre as partes.

A Constituição de 1988 previu, de certa forma, a necessidade de estipular regras de proteção aos cidadãos, reconhecendo-lhes direitos na condição de fundamentais como: educação, saúde, trabalho, moradia, lazer, segurança, previdência social, entre outros. Os direitos sociais como categoria normativa, que, se não concretizados, daria ao Poder Judiciário o poder de agir como controlador das promessas constitucionais. Assim: para que as normas constitucionais não sejam relegadas à condição programática sem eficácia mandamental, se reconhece ao Poder Judiciário a capacidade de dar força normativa aos direitos sociais, podendo imprimir na realidade a emancipação social através da constituição ${ }^{37}$.

A intervenção do Poder Judiciário para realização das políticas públicas vem sendo conhecida como a judicialização da política como movimento histórico-político posterior a mudança de regimes autoritários até a consolidação das instituições democráticas ${ }^{38}$, como é o caso brasileiro. Portanto,

37 STRECK, Lenio Luiz. Jurisdição constitucional e hermenêutica: uma nova crítica do direito.

2. ed. Rio de Janeiro: Forense, 2004, p. 112.

38 VIANNA, Luiz Werneck. A judicialização da política e das relações sociais no Brasil. Rio de Janeiro: Revan, 1999, p. 149. 
passa a ser o caminho mais acessível e rápido à consecução dos direitos constitucionalmente consagrados institucionalmente ${ }^{39}$.

Tendo como premissa o referido fenômeno da judicialização das políticas públicas, surge o questionamento sobre os limites de atuação do Poder Judiciário. Poderia o Poder Judiciário atuar na realização das promessas constitucionais sem qualquer limitação? Ou seja, ao verificar-se a omissão dos poderes legislativos e executivos poderia simplesmente o Poder Judiciário realizar as políticas públicas que bem entender como necessárias?

Essas indagações acabam por direcionar a atenção aos assuntos tratados pela teoria do direito e a hermenêutica jurídica, quando procuram pensar quais os critérios utilizados pelo Poder Judiciário para concretizar tais políticas públicas. Nessa perspectiva, portanto, adotar-se-á a Crítica Hermenêutica do Direito $^{40}$. Isso porque, grande parte das discussões doutrinárias coloca em evidência a relação existente entre o poder discricionário da administração pública como limite a atuação do Poder Judiciário. Entretanto, esse limite de atuação vem sendo suplantada pela articulação de princípios jurídicos como fundamento de revisão dos atos tidos como discricionários.

\subsection{A proporcionalidade como instrumento teórico-jurídico para aferição da atuação estatal}

No alerta de Streck, a característica própria do Estado Democrático de Direito seria a consideração dos Direitos Fundamentais como normas constitucionais, pelas quais, a moral institucionaliza-se no direito, indicando ideais de vida boa garantidos mediante um aparato de instrumentos processuais próprios a favorecer a sua concretização através da jurisdição constitucional, caracterizando um plus normativo ${ }^{41}$.

Assim, verificada violação aos Direitos Fundamentais, seja por ação ou omissão do Estado seja numa relação direta com os cidadãos ou indireta, pela falta de condições mínimas no desenrolar das relações privadas ${ }^{42}$, surge a obrigação jurídica de proteção a ser realizada. Dado o compromisso com os direitos fundamentais, o sistema jurídico é dotado de instrumentos processuais apropriados que garantam essa concretização, fazendo com que o dirigismo

39 SANTOS, Boaventura de Souza. Para uma revolução democrática da justiça. São Paulo: Cortez, 2007, p. 18.

${ }^{40}$ Marco teórico desenvolvido por Lenio Luiz Streck que, utilizando-se dos pressupostos teóricos da Filosofia Hermenêutica, Hermenêutica Filosófica e a teoria do direito de Ronald Dworkin, critica a qualidade democrática do direito brasileiro. Vide: STRECK, Lenio Luiz. Hermenêutica jurídica e $(m)$ crise: uma exploração hermenêutica da construção do direito. 8. ed. rev. atual. Porto Alegre: Livraria do Advogado Editora, 2009.

${ }^{41}$ STRECK, Lenio Luiz. Verdade e consenso: constituição, hermenêutica e teorias discursivas: da possibilidade à necessidade de respostas corretas em direito. 3. ed. rev. amp. Rio de Janeiro: Lumen Juris, 2009, p. 172.

${ }^{42}$ CANARIS, Claus-Wilhelm. Direitos Fundamentais e direito privado. Tradução Ingo

Wolfgang Sarlet e Paulo Mota Pinto. Coimbra: Edições Almedina, 2006, p. 58. 
constitucional saia do papel através da imposição de sua força normativa ${ }^{43}$ através do Poder Judiciário.

Com vista na doutrina e jurisprudência alemã, Mendes ${ }^{44}$ afirma que o dever de proteção envolveria: dever de proibição (Verbotsplifcht) de uma determinada conduta; dever de segurança (Sicherheitspflicht), protegendo os direitos do cidadão mediante instrumentos que coíbam atos de terceiros; dever de evitar riscos (Risikopflicht) protegendo o cidadão por medidas preventivas quanto ao desenvolvimento tecnológico. Deve o Estado, portanto, o possível para proteger os direitos fundamentais como bens jurídicos que devem ser preservados contra violações e ameaças antijurídicas ${ }^{45}$, não se conformando somente aos tradicionais direitos liberais negativos de proibição de intervenção (Eingriffsverbote), mas assumindo, como diz Mendes ${ }^{46}$, um postulado de proteção (Schutzgebote), implicando tanto na proibição do excesso (Übermassverbot) quanto na proibição de omissão (Untermassverbot).

A doutrina jurídica alemã, em observação as decisões do Tribunal Constitucional alemão (Bundesverfassungsgericht), formulou a teoria de que o dever de proteção exercido pelo Estado poderia ser aferido mediante aquilo que se convencionou como proporcionalidade. Especula-se que essa forma de enfrentar o problema conduziria a um modelo, método, generalizável para enfrentar os desafios que envolvessem os direitos fundamentais. $\mathrm{O}$ autor paradigma para esse desenvolvimento teórico é Robert Alexy.

Alexy sustenta que a proporcionalidade serve de máxima jurídica ${ }^{47}$ para a realização dos direitos fundamentais como princípios jurídicos e, nessa condição, veiculadores de mandamentos de otimização ${ }^{48}$. O autor desenvolve a metodologia da proporcionalidade tendo como pressuposto que os direitos fundamentais podem assumira estrutura de regras e princípios jurídicos. Aquelas forneceriam razões definitivas para a tomada de decisões (modelo tudo-ou-nada), enquanto que os princípios jurídicas imprimiriam razões prima face, diante do mandamento de otimização, exigindo que a conformação dos seus efeitos jurídicos estivesse vinculado as possibilidades do caso concreto investigado ${ }^{49}$.

Parece que um dos efeitos colaterais da teoria dos direitos fundamentais de Alexy, principalmente, decorrente da sua estrutura como princípios jurídicos, seria fundar-se na hipótese de que o caso concreto levado ao Poder Judiciário

43 Vide HESSE, Konrad. Elementos de direito constitucional da República Federativa da Alemanha. Tradução Luís Afonso Heck. Porto Alegre: Sérgio Antonio Fabris Editor, 1998.

44 MENDES, Gilmar. Hermenêutica constitucional e direitos fundamentais. Brasília: Brasília Jurídica, 2000, p. 210.

45 HESSE, 1998, p. 278.

${ }^{46}$ MENDES, 2000, p 209.

${ }^{47}$ ALEXY, Robert. Teoria dos Direitos Fundamentais. Trad. de Virgílio Afonso da Silva da $5^{\text {a }}$ edição alemã. São Paulo: Malheiros Editores, 2008, p. 116.

${ }^{48}$ Ibid., 2008, p. 90.

${ }^{49}$ ALEXY, 2008, p. 86-90. 
imprimiria constantes colisões entre princípios jurídicos ${ }^{50}$. Isso porque, sendo o princípio jurídico mandamento de otimização, o que exige sempre a sua satisfação pelo nível máximo, acabaria por colocar em choque diferentes mandamentos provenientes de diferentes princípios. A resolução desse problema acabaria exigindo do Judiciário o sopesamento ou ponderação entre princípios jurídicos, do qual se produziria uma norma de direito fundamental atribuída $^{51}$.

O Poder Judiciário seria responsável por produzir uma norma atribuída, cuja estrutura assumiria a condição de regra, sendo subsumível (sic) as condições fáticas em que se desenrolou a colisão de princípios jurídicos. Outro pressuposto que merece o seu devido esclarecimento é que a condição dos direitos fundamentais como princípios jurídicos seria um efeito da formulação constitucional de normas indeterminadas semântica ou estruturalmente ${ }^{52}$.

A próxima subsecção tem como finalidade apresentar decisões dos tribunais pátrios brasileiros que fazem referência a ponderação para o controle de políticas públicas, esclarecendo, desde já a equiparação teórica do termo com o sopesamento como solução teórico aquilo que ficou convencionado como colisão entre princípios jurídicos.

\subsection{Controle das políticas públicas como colisão entre princípios jurídicos: oclusão da discussão sobre o agir da administração pública}

As decisões referidas nesta subsecção não tem a pretensão de inferir que a ponderação seja o método (sic) dominante para o controle das políticas públicas pelo Poder Judiciário, mas visa, tão somente, procurar apresentar idiossincrasias de algumas das decisões que se utilizam dos princípios jurídicos como elementos deontológicos contributivos à resolução de problemas.

Também se deve esclarecer que as decisões referidas servem apenas para amostrar o problema da utilização dos princípios jurídicos como critérios para resolver questões jurídicas, tomando como emblemático a referência à ponderação como sinônimo a proporcionalidade e o arcabouço teórico que a envolve, nos termos já indicados na subsecção anterior.

Talvez o principal problema a ser enfrentado seja reconhecer que no regime democrático cada um dos órgãos responsáveis pelo exercício do poder tem responsabilidades limitadas a condições jurídicas e econômicas próprias. Somente nesse contexto é que se sustentaria pensar o ato da Administração Pública como exercício de um poder discricionário administrativo (juízo de oportunidade e conveniência) para gerir serviços públicos, sendo esses os meios que promovem as políticas públicas destinadas à realização das tarefas-fins constitucionais que legitimam o Estado. Nesse contexto, a escolha feita pelo administrador pode implicar na atuação de acordo com critérios previamente

\footnotetext{
${ }^{50}$ Ibid., 2008, p. 80.

${ }^{51}$ Ibid., 2008, p. 94-99.

${ }^{52}$ Ibid., 2008, p. 70.
} 
estabelecidos, na grande parte de suas vezes, mediante um planejamento publicizado.

Para tanto, assume-se a Lei como instrumento que, por excelência, atende os reclames democráticos da existência do Estado. Quando se pensa na administração pública, não se pode afastar que a constituição estabeleceu estruturas próprias que dão suporte aos procedimentos de tomadas de decisões sobre políticas públicas. Isto é, a própria Constituição, estrutura jurídica que conduz a atuação estatal prevê elementos como o Plano Plurianual (Constituição 1988 , artigo $165, \S 1^{\circ}$ ). Parece que, através dessa Lei que o Estado faz valer a sua qualidade de administrador. As suas escolhas devem estar contempladas pelo Plano Plurianual que, ao planejar as alternativas viáveis, consagra os meios que essas necessidades serão atendidas.

Quanto ao poder discricionário do Administrador Público, esse deveria estar fundado em estudos socioeconômicos, regionalizados, que indicassem concretamente as carências locais/regionais. Assim, como refere Bandeira de Mello ${ }^{53}$ "nos casos de discricionariedade, perante o dever jurídico de praticar, não qualquer ato dentre os comportados pela regra, mas, única e exclusivamente aquele que atenda com absoluta perfeição à finalidade da lei." Embora tenha o administrador o juízo de conveniência e oportunidade para realizar determinada ato, verificando-se a existência de demanda por direitos fundamentais comprovada por estudo socioeconômico específico, tem ele o dever de desenvolver meios para suprir essa carência, bem como prover os recursos necessários para tanto. A Administração Pública não pode fugir do seu dever primordial: gestão. Sustenta-se que tal dever de gestão implica na competência de investigar tecnicamente as carências sociais concretas, desenvolvendo planos hábeis para executar medidas que suprimam a deficiência.

A questão poderia ser proposta de outra forma: quais os limites do Poder Judiciário para promover o controle das leis orçamentárias? Não seriam essas leis públicas e, dessa maneira, decorrentes de um procedimento democrático que aponta as carências sociais, fundada em estudos prévios socioeconômicos? Se assim comprovado, parece ser forçoso substituir a decisão política pela jurídica. Se houve estudo técnico socioeconômico que embasa a indicação das carências sociais, especula-se que o Poder Judiciário seria o menos qualificado para controlar os atos da administração pública. Isso pois, não teria ele, a priori, a mesma capacitação técnica.

Essa discussão proposta, na qual se coloca em evidência a qualidade de administrador como capacidade de investigar cientificamente as carências sociais e vincular a elas recursos necessários que fomentem a realização de serviços públicos para concretizar os fins constitucionais, não é o que se vê na prática jurisprudencial. Parece que essas discussões, talvez pela sua complexidade, surgem apenas marginalmente no Poder Judiciário através da indicação nominativa da reserva do possível. Toda a complexidade da análise

${ }^{53}$ BANDEIRA DE MELLO, Celso Antônio. Discricionariedade e controle jurisdicional. 2. ed. São Paulo: Editora Malheiros LTDA, 2006, p. 33. 
quanto ao planejamento socioeconômico do administrador é abstraído e representado pela reserva do possível, sem o devido conhecimento da sua gênese representativa.

A chamada reserva do possível surgiu na decisão do Tribunal Constitucional alemão que reconheceu a impossibilidade da prestação exigida para que fossem criadas vagas nas universidades públicas na mesma quantidade de candidatos submetidos ao concurso. A decisão tornou-se paradigmática pelo fato de que a prestação exigida pode ser atendida tendo como limite aquilo que razoavelmente se pode esperar do Estado ${ }^{54}$.

A práxis brasileira veio a utilizar a medida do possível como argumento para justificar a impossibilidade do Poder Judiciário dispor de medidas de políticas públicas que impliquem num aumento de gastos orçamentários. $\mathrm{O}$ sentido da reserva do possível passa a ser compreendido sob a ótica da possibilidade econômica financeira do Estado em prestar as medidas postuladas judicialmente, afastando-se do seu sentido originário utilizado pelo Tribunal Constitucional alemão.

É certo que a análise quanto a possibilidade econômica da administração para o cumprimento das medidas exigidas pelos cidadãos deve ser apreciado com responsabilidade, todavia, não serve de salvaguarda para que a concretização de políticas públicas previstas legalmente deixem de ser atendidas, sob a desculpa que os cofres estão vazios. Isso implicaria em admitirse que os direitos sociais somente se revestiriam de eficácia quando houver recursos suficientes para tanto, condenando-lhes a concepção de direitos de segunda categoria, como afirma Krell ${ }^{55}$. Aliás, aproveitando-se do mesmo autor, aponta que a disparidade existente entre os orçamentos dos entes federais impede que seja reconhecido aquilo que efetivamente é seria possível economicamente de ser cumprido ${ }^{56}$. Continuando a crítica, o autor enfatiza que num país como o Brasil onde a redistribuição de renda não atinge os seus fins esperados não seria possível limitar as prestações necessárias aos direitos sociais em razão de limitações orçamentárias.

Todavia, indiferente a essas questões, é possível destacar algumas decisões dos tribunais pátrios que se utilizam da reserva do possível na qualidade de princípio jurídico para que possa ser ponderado juntamente com outro princípio (sic), idealizado ad hoc, proporcionando a indicação formal da aplicação da ponderação como método utilizado para resolução do problema jurídico. Apenas exemplificativamente, indica as seguintes decisões:

ADMINISTRATIVO. OMISSÃO NO OFERECIMENTO DE TRATAMENTO MÉDICO ADEQUADO. NECESSIDADE DE CATETERISMO CARDÍACO, ANGIOPLASTIA E IMPLANTE DE STENT. RESPONSABILIDADE CIVIL SUBJETIVA.

\footnotetext{
${ }^{54}$ KRELL, Andreas. Direitos Sociais e Controle Judicial no Brasil e na Alemanha: os (des)caminhos de um direito constitucional comparado. Porto Alegre: Fabris, 2002, p. 52.

55 Ibid., loc. cit.

${ }^{56}$ Ibid., 2002, p. 53.
} 
ATENDIMENTO PARTICULAR. RISCO DE VIDA. LEGITIMIDADE PASSIVA DOS ENTES PÚBLICOS. RESERVA DO POSSÍVEL. PONDERAÇÃO COM OUTROS PRINCÍPIOS. DIREITO AO RESSARCIMENTO DE DESPESAS MÉDICAS COMPROVADAS. DANO MORAL NÃO CONFIGURADO.(250 RS 2005.71.02.000250-8, Relator: MARIA LÚCIA LUZ LEIRIA, Data de Julgamento: 06/04/2010, TERCEIRA TURMA, Data de Publicação: D.E. 12/05/2010)

AGRAVO DE INSTRUMENTO. AÇÃO CIVIL PÚBLICA. FORNECIMENTO DE MEDICAMENTO. PRELIMINAR DE ILEGITIMIDADE PASSIVA AFASTADA. RESPONSABILIDADE SOLIDÁRIA DOS ENTES FEDERATIVOS. AUSÊNCIA DE PADRONIZAÇÃO E COMPROVAÇÃO DE EFICÁCIA DO MEDICAMENTO PLEITEADO. IRRELEVÂNCIA. PREPONDERÂNCIA DA INDICAÇÃO DO MÉDICO ESPECIALISTA. PRINCÍPIO DA RESERVA DO POSSÍVEL. INAPLICABILIDADE AO CASO CONCRETO. PONDERAÇÃO DE VALORES. PRINCÍPIO DA PROPORCIONALIDADE. FIXAÇÃO DE MULTA DIÁRIA CONTRA A FAZENDA. POSSIBILIDADE. RECURSO DESPROVIDO. (5781248 PR 0578124-8, Relator: Abraham Lincoln Calixto, Data de Julgamento: 09/11/2009, 4ª Câmara Cível, Data de Publicação: DJ: 279)

Controle judicial das políticas públicas de saúde. Necessidade de analisar cada caso concreto. Teoria das reservas do possível e insuficiente para afastar a análise do caso individualizado Procedimento de ponderação da teoria dos princípios e o meio a solucionar o conflito entre a teoria das reservas do possível e o dever de o Estado assegurar o núcleo essencial dos direitos fundamentais. Comprovação de que o caso em analise legitima a prevalência da intervenção judicial para assegurar o núcleo essencial do direito fundamental à saúde e o princípio da máxima eficiência das normas constitucionais. Ordem concedida. (4178715800 SP, Relator: Luis Manuel Fonseca Pires, Data de Julgamento: 22/08/2008, 8 a Câmara de Direito Publico A, Data de Publicação: 01/09/2008)

Essa forma de agir do Poder Judiciário parece não levar em conta a possibilidade de substituição do exercício de um poder discricionário pela administração pública, agora, pelo judiciário. Talvez, um dos indicativos seja reconhecer a limitação da concepção de princípios jurídicos utilizados pela jurisprudência pátria. A indicação desse problema pode promover questionamentos hermenêuticos fecundos, como se propõe na próxima subsecção.

\subsection{Desvelando a arbitrariedade no juízo ponderativo para controle das políticas públicas}

Para enfrentar a questão sobre a satisfação do dever de proteção, mediante as verificações de proibição de excesso e proteção insuficiente, a 
proporcionalidade (aqui levada em sinônimo com o método de ponderação) pode sofrer uma virada tornando-se fecunda como um impulso de vinculação do intérprete com a integridade e coerência da atuação estatal, com o reconhecimento de proteção aos Direitos Fundamentais que se pode esperar.

Nesse sentido, Streck vai falar que a proporcionalidade pode servir como uma metáfora, ou melhor, um modo de explicitar que a interpretação de determinado caso cumpriu com a necessária tarefa de reconstrução integrativa do direito ${ }^{57}$, contribuindo para enfrentar a questão da discricionariedade judicial oculta nas entranhas pragmáticas da aplicação da proporcionalidade.

A proporcionalidade concebida dessa maneira obriga ao intérprete reconhecer a sua condição de ser-no-mundo, cujo significado das coisas se faz dependente do compartilhamento de uma determinada tradição, mais especificamente, lembrando-o da responsabilidade que o trato com o direito reclama, qual seja: a limitação do poder e das arbitrariedades provenientes dele.

Ainda com a análise de Streck sobre o assunto supra, pode-se reconhecer uma ruptura paradigmática, estabelecendo pelo Supremo Tribunal Federal que o legislador ordinário não poderia legislar contra bens jurídicos (Direitos Fundamentais) contemplados pela Constituição e, por este motivo, deveriam ser protegidos (Schutzpflicht). A decisão permite reconhecer uma (re)leitura da tradição jurídica, procurando uma solução que seja íntegra e coerente com o conjunto de princípios consagrados pelo sistema.

No contexto jurídico brasileiro a utilização da proporcionalidade ganha ares de arbitrariedade, talvez, em virtude da compreensão autentica do que seja o conceito de princípio jurídico. Diga-se de passagem, a arbitrariedade é um dos grandes problemas não superados do positivismo jurídico pelo direito brasileiro. Um exemplo disso é a concepção de que os princípios representam uma abertura à interpretação, não espantando, que "surjam", diariamente, cada vez mais princípios "criados" pelos intérpretes para sustentar a sua interpretação.

Nesse sentido, Streck $^{58}$ identifica um panpricipiologismo no sistema jurídico brasileiro de tal forma que a inflação por eles provocada, como pensa o senso comum teórico, não poderia ser outro do que a existência de constante colisão entre os princípios, principalmente, considerando-os refratários a sua concepção como mandamentos de otimização. Não seria surpresa, portanto, que muitas das demandas que envolvem a realização das políticas públicas acabam se socorrendo da existência (sic) de princípios jurídicos criados ad hoc, que, pelo método da ponderação proporcionariam o resultado justo para a demanda judicial. E os critérios previstos pelo sistema jurídico através de leis orçamentarias seriam legadas a um segundo plano? $O$ planejamento administrativo poderia sempre ser desprezado? O problema que se impõe com a utilização do método de ponderação (princípio da prorporcionalidade, sopesamentos) estaria na substituição da arbitrariedade administrativa pela

57 DWORKIN, Ronald. Levando os direitos a sério. Trad. Nelson Boeira. São Paulo: Martins Fontes, 2002.

58 STRECK, 2009, p. 475. 
arbitrariedade judicial. Ambas, na concepção desenvolvida, insubsistentes com o modelo de Estado Democrático de Direito.

Repristina-se toda a crítica hermenêutica ao método como produto da subjetividade do intérprete. $\mathrm{O}$ recurso feito ao mito do método de ponderação guarda sob um enunciado performativo o exercício da arbitrariedade do intérprete que estaria fora do objeto da interpretação. Não seria preciso muito esforço filosófico para reconhecer o problema dos efeitos proporcionados pelo esquema epistemológico do sujeito objeto. Poderia o intérprete (legislador, administrador ou, principalmente no caso, o juiz) através da proteção do método de ponderação escolher que princípio jurídico ofereceria a solução idealizada pelo sujeito. O sujeito acabaria por sujeitar o objeto da interpretação ${ }^{59}$.

Como que a hermenêutica jurídica poderia (não) resolver a questão? (sic) Ora, já foi indicada a solução adotada, quer dizer, recorre-se ao princípio epocal que conforma a comunidade jurídica: o princípio da proporcionalidade. $\mathrm{O}$ referido princípio é lançado a uma condição de plenipontenciariedade principiológica $^{60}$, servindo como solução a todos os problemas provocados pelo congestionamento de princípios. A consequência não poderia ser outra senão a utilização da metaregra proporcionalidade para conformar a anarquia provocada pelos demais princípios.

Só que o princípio da proporcionalidade entendido como uma fórmula hermenêutica descolada da realidade ontológica-existencial não possui qualquer sentido que não uma referência retórica que encobre os critérios utilizados pelo julgador para resolver os problemas trazidos pelo caso concreto. Por isso, podese especular, por exemplo, que Streck refere que o princípio da proporcionalidade está sempre presente na aplicação do direito. Parece, assim, que a concepção sobre o princípio da proporcionalidade, utilizada pelo autor, rompe com o encobrimento do sentido que as estratificações do seu uso cotidiano despreocupado provocam. Procurando ser mais claro: a utilização do princípio da proporcionalidade, tanto na doutrina como da jurisprudência, escondem no não-dito, o seu critério dialógico, proporcionado por análises quanto à proibição do excesso (Übermassverbot) ou a proteção deficiente (Untermassverbot) de determinado ato estatal diante do reclame de coerência narrativa com a tradição jurídica. Parafraseando o autor: o princípio da proporcionalidade pode ser conhecido no seu "sentido de desproporção - seja negativo (Übermassverbot) ou positivo (Untermassaverbot) - somente poderá ser dado mediante a obediência a integridade do direito." ${ }^{.61}$.

$\mathrm{O}$ argumento parece simples, mas da sua simplicidade emerge a genialidade. Ou seja, quando se compreende o princípio da proporcionalidade como uma necessidade de por em diálogo a interpretação, como applicatio, do problema jurídico diante de uma leitura coerente com a integridade do sistema jurídico, seria possível identificar as falhas no exercício do poder, sejam elas

\footnotetext{
${ }^{59}$ Ibid., 2009.

${ }^{60}$ STRECK, 2009, p. 490.

${ }^{61}$ STRECK, loc. cit. 
por excesso ou deficiência. Essa claridade na reflexão provocada pelo critério duplo da proporcionalidade coloca o intérprete diante de uma responsabilidade junto ao sistema jurídico, devendo apontar argumentativamente que a sua compreensão evidenciou falhas quanto ao dever de proteção do Estado. Pode-se dizer que essa postura proporciona um salto democrático qualitativo ao fazer com que o intérprete apresente a falha do ato impugnado diante de uma obrigação do Estado consagrada no sistema jurídico. Parece que, nessa postura, a utilização decisionista do princípio da proporcionalidade é substituída por uma publicidade e transparência democrática decorrente da necessidade de demonstração intersubjetiva da violação do dever de proteção.

Isso porque, ter-se-ia que enfrentar argumentativamente os problemas quanto ao planejamento das políticas públicas, por exemplo, explicitando os motivos socioeconômicos que as qualificam como deficitárias. Parece, com vistas a jurisprudência amostrada, que esse esforço argumentativo é substituído pela oclusão performativa da ponderação. Traça-se, a partir de então, a diferença entre escolher e decidir sobre a propriedade das políticas públicas ${ }^{62}$. Se o ato de escolher está escorado no método de ponderação, a (re)leitura da proporcionalidade nos moldes propostos implica numa decisão. No direito o que se pretende é decidir. Decidir é comprometer-se com algo que se antecipa ${ }^{63}$. É estar vinculado aos critérios consagrados em determinada tradição (comunidade política que constrói o direito ${ }^{64}$, exigindo do juiz, no caso, a sua responsabilidade de engajamento ${ }^{65}$.

Por sua vez, a argumentação, justificação, ou, para ser melhor compreendido, o dever de fundamentação (CF, Art. 93, IX), permite que a jurisprudência cumpra o seu papel de re-produtor da tradição jurídica, denunciando as deficiências do dever de proteção do Estado, auxiliando na institucionalização dos limites do sentido jurídico constitucional à autonomia do direito, preocupação esta, que não atinge os hermeneutas adeptos ao princípio da proporcionalidade para controle das políticas públicas, sem os cuidados apontados.

\section{CONSIDERAÇÕES FINAIS}

O dilema sobre a efetividade dos direitos sociais pode ser enfrentado, segundo as perspectivas teóricas apresentadas, sob dois níveis diferentes de debate: o primeiro, de caráter filosófico político, analisa a questão do controle judicial da efetivação dos direitos sociais a partir da compreensão condição humana, que está associada ao acesso do sujeito ao espaço público; o segundo, diz respeito à atuação do Judiciário no processo decisório, que, uma vez

${ }^{62}$ STRECK, 2010, p. 105-106.

63 STRECK, p. 106

64 Ibid., loc. cit.

65 DWORKIN, Ronald. O império do direito. Trad. Jeferson Luiz Camargo. São Paulo: Martins Fontes, 2003, p. 291. 
baseado na crítica hermenêutica do direito, legitima o controle judicial da efetividade dos direitos sociais, sem o excesso de tornar-se arbitrário.

Verificou-se que na concepção arendtiana de esfera pública, que é a realidade do comum, construída pela fundamental participação do sujeito no espaço público, tem o pressuposto da condição humana. A partir dessa fundamentação é possível afirmar que espaço público não está restrito ao espaço da representação democrática, razão porque compreender eficácia social de direitos sociais é, antes de tudo, perceber que a satisfação de uma necessidade básica está diretamente ligada à potencialidade do sujeito de ser visto e ouvido a partir do seu contexto sociocultural. Portanto, o Estado, representado pelo Legislativo e Executivo não pode atribuir às vias formais da representação democrática o canal único de escolhas públicas e de decisão sobre efetividade de direitos sociais, de que é corolário o pensamento sobre a chamada reserva do possível. O Judiciário, de outro lado, possui o dever de reconhecer esse direito humano de voz e ação do sujeito, pelo direito constitucional de acesso à justiça, e ponderar, para além de qualquer limite orçamentário e discricionário da Administração Público, sobre o que é satisfação de direitos sociais e, portanto, prestar jurisdicionalmente a eficácia social de direitos negligenciados no plano dos fatos.

Do ponto de vista do controle judicial das políticas públicas analisou-se o desafio da arbitrariedade do Judiciário. Isso porque, ao invés de pensar-se em critérios jurídicos democráticos para aferição das tarefas do Estado, como um imperativo de proteção, o caminho seguido pelo Poder Judiciário tem sido o recurso ao método de ponderação entre princípios jurídicos que, por vezes, descuida-se do arcabouço teórico que lhe deu suporte, bem como deixa de cumprir com o dever de fundamentação das decisões judiciais, dando à solução ares de mitologia, redundando, apenas, na substituição da arbitrariedade das escolhas do administrador pelas do julgador.

\section{REFERÊNCIAS}

ALEXY, Robert. Teoria dos Direitos Fundamentais. Trad. de Virgilio Afonso da Silva da $5^{a}$ edição alemã. São Paulo: Malheiros Editores, 2008.

ARENDT, Hannah. A condição humana. $10^{\mathrm{a}}$ ed. Trad. Roberto Raposo. Rio de Janeiro: Forense Universitária, 2004.

BANDEIRA DE MELLO, Celso Antônio. Discricionariedade e controle jurisdicional. 2. ed. São Paulo: Editora Malheiros LTDA, 2006.

CANOTILHO, José Joaquim Gomes. Constituição Dirigente e vinculação do legislador: contributo para a compreensão das normas constitucionais programáticas. Reimp. Coimbra: Coimbra Editora, 1994.

CANARIS, Claus-Wilhelm. Direitos Fundamentais e direito privado. Tradução Ingo Wolfgang Sarlet e Paulo Mota Pinto. Coimbra: Edições Almedina, 2006.

DERRIDA, Jacques. Força de Lei. Trad. Leyla Perrone-Moisés. São Paulo: Martins Fontes, 2007. 
DWORKIN, Ronald. O império do direito. Trad. Jeferson Luiz Camargo. São Paulo: Martins Fontes, 2003.

. Levando os direitos a sério. Trad. Nelson Boeira. São Paulo: Martins Fontes, 2002.

GRIMM, Dieter. A função protetiva do Estado. In: SOUZA NETO, Cláudio Pereira de; SARMENTO, Daniel. (Coords.). A constitucionalização do direito: fundamentos teóricos e aplicações específicas. Rio de Janeiro: Editora Lumen Juris, 2007, p. 149-165.

HESSE, Konrad. Elementos de direito constitucional da República Federativa da Alemanha. Tradução Luís Afonso Heck. Porto Alegre: Sérgio Antonio Fabris Editor, 1998, p. 278.

. A força normativa da Constituição. Trad. Gilmar Ferreira Mendes.

Porto Alegre: Sérgio Antonio Fabris, 1991.

KRELL, Andreas. Direitos Sociais e Controle Judicial no Brasil e na Alemanha: os (des)caminhos de um direito constitucional comparado. Porto Alegre: Fabris, 2002.

LEFEBVRE, Henri. $O$ direito à cidade. Trad. Rubens Eduardo Frias. São Paulo: Centauro, 2009.

MENDES, Gilmar. Hermenêutica constitucional e direitos fundamentais. Brasília: Brasília Jurídica, 2000.

PEREIRA, Potyara A. P. Necessidades humanas: subsídios a crítica dos mínimos sociais. São Paulo: Cortez, 2000.

SANTOS, Boaventura de Souza. Para uma revolução democrática da justiça. São Paulo: Cortez, 2007.

SARLET, Ingo Wolfgang A eficácia dos direitos fundamentais. 2 ed. Porto Alegre: Livraria do Advogado, 2001.

SILVA, José Afonso. Aplicabilidade das normas constitucionais. 6. ed. São Paulo: Malheiros Editores, 2004.

STRECK, Lenio. O que é isto - decido conforme minha consciência? 2. ed. rev. amp. Porto Alegre: Livraria do Advogado Editora, 2010.

Verdade e consenso: constituição, hermenêutica e teorias discursivas:

da possibilidade à necessidade de respostas corretas em direito. 3. ed. rev. amp.

Rio de Janeiro: Lumen Juris, 2009.

. Hermenêutica jurídica e $(m)$ crise: uma exploração hermenêutica da

construção do direito. 8. ed. rev. atual. Porto Alegre: Livraria do Advogado

Editora, 2009.

. Jurisdição constitucional e hermenêutica: uma nova crítica do direito.

2. ed. Rio de Janeiro: Forense, 2004.

VIANNA, Luiz Werneck. A judicialização da política e das relações sociais no Brasil. Rio de Janeiro: Revan, 1999.

Recebido em 30-09-2011

Avaliado em 14-11-2011

Aprovado para publicação em 05-12-2011 